\title{
Effect of all-trans retinoic acid on newly diagnosed acute promyelocytic leukemia patients: results of a Brazilian center
}

B.C. de-Medeiros,

E. Strapasson, R. Pasquini and C.R. de-Medeiros
Serviço de Transplante de Medula Ó ssea, Hospital de Clínicas,

Universidade Federal do Paraná, Curitiba, PR, Brasil

\section{Correspondence C.R. de-M edeiros \\ Serviço de Transplante de Medula Ó ssea, Hospital de Clínicas, UFPR \\ R. General Carneiro, 181, 15ำ andar 80060-900 Curitiba, PR \\ Brasil \\ Fax: + 55-41-264-5472}

Received January 15, 1998

Accepted August 5, 1998

\begin{abstract}
Thirty-seven patients with acute promyelocytic leukemia (APL) were treated with all-trans retinoic acid (ATRA). Patients received $45 \mathrm{mg} \mathrm{m}^{-2}$ day ${ }^{-1}$ po of ATRA until complete remission (CR) was achieved, defined as: a) presence of less than $5 \%$ blasts in the bone marrow, with b) white blood cells $>10^{3} / \mathrm{mm}^{3}$, c) platelets $>10^{5} / \mathrm{mm}^{3}$ and d) hemoglobin concentration $>8 \mathrm{~g} / \mathrm{dl}$, with no blood or platelet transfusions. Thirty-one (83.7\%) patients achieved CR by day 50 , and $75 \%$ of these before day 30 . Correction of the coagulopathy, achieved between days 2 and 10 (mean, 3 days), was the first evidence of response to treatment. Only one patient had been previously treated with chemotherapy and three had the microgranular variant M3 form. Dryness of skin and mucosae was the most common side effect observed in $82 \%$ of the patients. Thrombosis, hepatotoxicity and retinoid acid syndrome (RAS) were observed in 7 (19\%), $6(16 \%)$ and 4 (11\%) patients, respectively. Thirteen (35\%) patients had to be submitted to chemotherapy due to hyperleukocytosis (above $40 \times 10^{3} / \mathrm{mm}^{3}$ ) and six of these presented with new signs of coagulopathy after chemotherapy. Four (11\%) patients died secondarily to intracerebral hemorrhage $(\mathrm{IH})$ and two $(5.4 \%)$ dropped out of the protocol due to severe ATRA side effects (one RAS and one hepatotoxicity). RAS and IH were related strictly to hyperleukocytosis. The reduced use of platelets and fresh frozen plasma probably lowered the total cost of treatment. We conclude that ATRA is an effective agent for inducing complete remission in APL patients.
\end{abstract}

\section{Introduction}

Acute promyelocytic leukemia (APL), or M3 in the French-American-British classification, represents $5-15 \%$ of cases of acute myeloid leukemia (AML) (1). This distinct subset of AML is associated with the presence of abnormal promyelocytes in the blood

\section{Key words}

- All-trans retinoic acid

- Acute promyelocytic

leukemia

- Retinoid acid syndrome 
elocytic leukemia gene with the gene for retinoic acid receptor alpha (3). As demonstrated initially by Huang et al. (4), patients with APL have a high response rate to differentiation therapy with all-trans retinoic acid (ATRA), even though complete remission (CR) has not been sustained by ATRA therapy alone (5). One major advantage of the ATRA schedule is that it results in rapid disappearance of DIC (4), mainly through cytodifferentiation rather than immediate lysis of leukemic cells. However, some new life-threatening retinoid-induced complications, such as leukocytosis, retinoid acid syndrome (RAS) and thromboembolic events, have been demonstrated in a significant number of cases (6). In spite of several studies reporting the efficacy of the differentiating therapy with ATRA, no reports have been published thus far in the Brazilian literature. The authors present 37 patients with APL from two major cancer centers from Curitiba, Brazil, where induction therapy, toxicity and treatment costs of ATRA were assessed.

\section{Patients and Methods}

\section{Patients and eligibility criteria}

Between March 1992 and November 1995, 37 patients (Table 1) diagnosed with APL from Hospital de Clínicas and Hospital Nossa Senhora das Graças, Curitiba, were included in a clinical trial to evaluate the efficacy of ATRA in inducing CR and its toxicity. Patients or their legal representatives gave informed consent to participate in the experimental study, which was approved by the Ethics Commissions of both hospitals. Inclusion criterion was a diagnosis of APL based on FAB group morphology criteria (7). Although cytogenetic evaluation for $\mathrm{t}(15 ; 17)$ was attempted for most patients, demonstration of the PML-RAR $\alpha$ protein was not required as a criterion for eligibility. Prior to the beginning of ATRA therapy, complete coagulation studies and normal hepatic and renal function tests were required.

\section{Protocol design}

Patients received $45 \mathrm{mg} \mathrm{m}^{-2}$ day $^{-1}$ po of ATRA (Tretinoína, Roche Pharmaceuticals, São Paulo, Brazil) until day 50 of ATRA or refractoriness was demonstrated. When the coagulopathy was still present beyond the 10th day of treatment, ATRA was increased to $90 \mathrm{mg} \mathrm{m}^{-2}$ day $^{-1}$ po for 5 additional days. If no correction of DIC occurred, aggressive chemotherapy was started. CR was defined on days +30 or +50 of ATRA therapy on the basis of peripheral blood counts and bone marrow aspiration and biopsy studies as: 1) presence of less than $5 \%$ blasts in the bone marrow, with 2) white blood cells $>10^{3} /$ $\mathrm{mm}^{3}, 3$ ) platelets $>10^{5} / \mathrm{mm}^{3}$ and 4) hemoglobin concentration $>8 \mathrm{~g} / \mathrm{dl}$, with no blood or platelet transfusions. Red blood cell transfusion was used to maintain hemoglobin levels above $8 \mathrm{~g} / \mathrm{dl}$ and platelet transfusion was performed to maintain platelet count above $20 \times 10^{3} / \mathrm{mm}^{3}$. Fresh frozen plasma and cryoprecipitate transfusions were performed in patients with any evidence of coagulopathy (6). Patients with severe thrombotic phenomena such as pulmonary embolism and large vein thrombosis received heparin 5000 $\mathrm{U} i v \mathrm{q} 4 \mathrm{~h}$ for 10 days, followed by heparin $5000 \mathrm{U} s c$ bid until the end of the ATRA therapy. Those who reached white blood cell count (WBC) above $40 \times 10^{3} / \mathrm{mm}^{3}$ were managed with cytosine arabinoside $(500 \mathrm{mg} /$ $\left.\mathrm{m}^{2}, i v\right)$ and daunomycin $\left(60 \mathrm{mg} / \mathrm{m}^{2}, i v\right)$ in order to decrease tumor mass. RAS, characterized by unexplained fever, weight gain, respiratory distress, interstitial pulmonary infiltrates, pleural and pericardial effusions, and generally accompanied by leukocytosis (8), was managed with dexamethasone 10 $\mathrm{mg} i v$ bid for at least 3 days. Antibiotics were given as supportive treatment when necessary (findings of localized infection or fever of unknown origin in patients with granulocyte counts below $500 / \mathrm{mm}^{3}$ ). 


\section{Laboratory follow-up}

Daily complete blood cell counts (CBC) and coagulation studies were performed after initiating the ATRA therapy until stabilization of leucocytes and correction of coagulopathy, respectively. The studies were repeated once a week until day +30 or +50 of ATRA therapy. A bone marrow aspirate was obtained on days +30 and +50 to check for $\mathrm{CR}$. Hepatic and renal function tests were performed weekly during hospitalization and twice a month thereafter.

\section{Endpoints}

The major endpoints of this study were: 1) intolerance to ATRA, 2) maintenance of the coagulopathy beyond day 15 of ATRA therapy, 3) no CR after day 50, and 4) resistance to ATRA.

\section{Results}

\section{Response to therapy}

CR was achieved in 31 (83.7\%) patients, by day 30 of ATRA treatment in 23 of them and by day 50 in 8 , and no patient had the drug discontinued because of resistant disease. Correction of the coagulopathy was the first evidence of response to ATRA and was detected in 34 patients between days 2 and 10 (mean, 3 days). Thirteen patients had to be submitted to chemotherapy due to elevated WBC (above $40 \times 10^{3} / \mathrm{mm}^{3}$ ) and six of these presented with new signs of coagulopathy after chemotherapy. Four (10.8\%) patients died secondarily to central nervous system bleeding on days $+4,+5,+7$ and +18 . Two had early death while on ATRA therapy only and two died after chemotherapy due to elevated WBC, and all four had leucocytes above $40 \times 10^{3} / \mathrm{mm}^{3}$ at the time of death. Two patients dropped out of the protocol due to severe ATRA side effects (RAS in one and hepatotoxicity in the other). Median
WBC was $2.4 \times 10^{3} / \mathrm{mm}^{3}$ (range 0.6 to $52 \mathrm{x}$ $10^{3} / \mathrm{mm}^{3}$ ) for all patients at diagnosis, reaching a maximum of $24.3 \times 10^{3} / \mathrm{mm}^{3}$ (range 4.2 to $100.6 \times 10^{3} / \mathrm{mm}^{3}$ ) in all patients alive between days +6 and +19 (mean, +15 days) after initiating ATRA treatment.

\section{Toxicity}

The most common side effect of ATRA therapy was dryness of skin and mucosae in $82 \%$ (28) of the patients, which developed from the first to the third week. Severe thrombosis was observed in $7(19 \%)$ patients, but only one had a WBC above $20 \times 10^{3} / \mathrm{mm}^{3}$. RAS was diagnosed in $4(11 \%)$ patients on days $+3,+5,+10$ and +15 of ATRA treatment. One of these patients received chemotherapy ordered by the attending physician instead of the proposed RAS treatment, and was excluded from the protocol. These patients presented a maximum median $\mathrm{WBC}$ of $48 \times 10^{3} / \mathrm{mm}^{3}$, compared to $22.5 \times 10^{3} / \mathrm{mm}^{3}$ ( $\mathrm{P}<0.05$, Fisher's test (9)) in patients with no RAS. Six patients presented increased values of liver function tests, but only one had

\begin{tabular}{ll} 
Table 1 - Characterization of the patient population. \\
\hline Characteristics & \\
\hline Number of patients & 37 \\
Age, years (range) & $17.5(9-69)$ \\
Sex (M/F) & $17 / 20$ \\
Morphology & \\
Classical M3 & 34 \\
Microgranular variant M3 & 3 \\
Clinical status & \\
Fever & $10(27 \%)$ \\
Bleeding & $10(27 \%)$ \\
Ecchymosis & $34(92 \%)$ \\
Laboratory data (range) & \\
WBC/mm 3 & \\
Classical M3 & $3000(600-51200)$ \\
Microgranular variant M3 & $26200(5600-52000)$ \\
Hemoglobin (g/dl) & $8.0(4.0-12.3)$ \\
Platelets/mm 3 & $21000(9000-162000)$ \\
Peripheral blood blasts (\%) & $56(0-94)$ \\
Fibrinogen (mg/dl) & $189(44-360)$ \\
PT (s) & $17.1(12-42)$ \\
PTT (s) & $34.6(17-65)$ \\
&
\end{tabular}


severe intrahepatic cholestasis with liver function tests reaching values 8 times higher than the normal upper limit and was withdrawn from the protocol.

\section{Supportive care and hospitalization}

Hospitalization varied from 0 to 50 days (mean, 19 days). The amount of blood components utilized during this time is summarized in Table 2. The amount of platelets and fresh frozen plasma transfused in the ATRA group was significantly less than for the chemotherapy group, $31.7 \mathrm{IU}$ versus $135 \mathrm{IU}$ $(\mathrm{P}=0.05)$ and $100 \mathrm{ml}$ versus $1,330 \mathrm{ml}$ $(\mathrm{P}<0.01)$, respectively. Thirteen patients had to be managed with antibiotics (one due to periodontitis, one due to tonsillitis, another due to scrotal sac cellulitis and the rest due to fever of unknown origin during the leukopenic period).

\section{Discussion}

APL is a distinct subgroup of AML with specific clinical and molecular features. Over the last few years, the introduction of ATRA has opened new perspectives for the treatment and understanding of several of its leukemic mechanisms. This study shows the differentiating capacity of ATRA as an inductor of CR, with $83.7 \%$ of the newly diagnosed patients achieving CR during the course of treatment. Such remission rates are similar to those obtained in several other randomized trails with ATRA $(4,10)$ and also to the historical results obtained with

$\begin{aligned} & \text { Table } 2 \text { - Utilization of blood components in ATRA } \\
& \text { patients. }\end{aligned}$
\begin{tabular}{lc} 
Blood component & $\begin{array}{c}\text { Median amount of blood } \\
\text { components (IU/patient) }\end{array}$ \\
\hline Platelets & 37.2 \\
Red blood cells & 3.6 \\
Fresh frozen plasma & 12.5 \\
Fresh plasma & $180 \mathrm{ml}$
\end{tabular}

Table 2 - Utilization of blood components in ATRA standard chemotherapy (11).

DIC is the most common complication of APL and its severity and frequency are often aggravated by chemotherapy, as was the case for 6 of our patients. Although patients submitted to chemotherapy frequently reach CR, they usually need intensive blood support to prevent bleeding, attributed to the release of both procoagulatory and fibrinolytic substances from damaged malignant cells, low fibrinogen levels and worsening of thrombocytopenia. In our own service, we compared historical data of 28 patients treated with chemotherapy alone from 1985 to 1992 with those for the group treated with ATRA. The first evidence of a response to ATRA in our patients was correction of the coagulopathy (mean, 3 days), with a rapid resolution of fibrinolysis and fibrinogenopenia, consequently reducing the amount of blood components needed and the possible implications of hemorrhagic diathesis, as reported by several other authors $(9,12,13)$.

Leukocytosis, an adverse effect of ATRA therapy in APL (14), which occurred in $37 \%$ of our patients, is due to an increase in circulating maturing blast cells secondary to cytodifferentiation rather than leukemic cell lysis, and is not observed during conventional intensive chemotherapy. The high number of circulating blasts increases blood viscosity and is associated with leukoblastic emboli, resulting in leukostasis of the small vessels. Furthermore, the leukemic blasts can infiltrate the arteriolar endothelial walls and cause a secondary hemorrhage (15). Therefore, a major concern about APL patients treated with ATRA is early death secondary to hyperleukocytosis during induction treatment $(11,16)$, especially due to RAS and intracerebral hemorrhage. In our study, 4 of 37 patients (11\%) had an early death due to intracerebral hemorrhage, with a higher median WBC than in the group that did not develop this lethal complication (48 x $10^{3} / \mathrm{mm}^{3}$ versus $22.5 \times 10^{3} / \mathrm{mm}^{3}$ ). RAS also occurred only in patients whose leuko- 
cytes were above $40 \times 10^{3} / \mathrm{mm}^{3}$ (4 of 13 patients).

In order to avoid hyperleukocytosis and its complications, the French group designed a protocol whose major goal was to prevent the increase in leukocyte counts by the early use of chemotherapy in combination with ATRA $(17,18)$, but this strategy barely improved their CR rates. Vahdat et al. (19), analyzing the concept of full-dose chemotherapy based on the peripheral blood leukocyte count proposed by the French group, demonstrated that chemotherapy actually contributes to excess early mortality due to the reappearance of the bleeding diathesis, a fact that was also observed in the present study. Indicating how hard it is to establish an ideal leukocyte parameter for the combination of early chemotherapy with ATRA, several Chinese reports have found a very low incidence of RAS despite very high leukocyte counts $(4,5,20)$. In agreement with Fenaux et al. (21), we may speculate about the presence of genetic predisposition to RAS among different populations, explaining these intriguing differences.

In our group, 3 of the 4 patients with RAS were managed with a short course of highdose dexamethasone and had their abnormalities corrected, just as demonstrated by others $(8,22)$. Based on these results, the serious complications of RAS have been almost entirely eliminated with a liberal policy of steroid administration, substantially reducing mortality. We note, however, that this approach mandates careful patient monitoring, particularly with respect to fluid balance and renal function. As a step ahead in the management of these patients, how would one avoid the occurrence of RAS? Strategies such as prophylactic corticosteroids $(22,23)$, concomitant use of ATRA and hydroxyurea (22) and lower doses of ATRA (20) $\left(15\right.$ to $\left.25 \mathrm{mg} / \mathrm{m}^{2}\right)$ have been applied with acceptable results, but not yet evaluated in randomized trials.

As in other subtypes of acute leukemias,
APL patients show a strict relationship between leukocytosis and severe hemorrhage. In our group, 4 patients died of intracerebral hemorrhage and all had leukocyte counts above $40 \times 10^{3} / \mathrm{mm}^{3}$ at the time of bleeding, versus a $22 \times 10^{3} / \mathrm{mm}^{3}$ leukocyte count in patients who did not present this complication. Since all our patients were submitted to the same approach in terms of platelet transfusion and the coagulation abnormalities had been corrected at time of death, we conclude that hyperleukocytosis is probably involved in the etiology of retinoid-induced intracerebral hemorrhage.

ATRA therapy rapidly corrects the bleeding diathesis and normalizes the fibrinogen levels of APL patients. However, a procoagulant tendency persists due to the existence of low grade DIC which accounts for the thrombotic events seen as late as 1 month after ATRA therapy (24) and for the 10\% hemostatic death rate reported among these patients (25). Furthermore, patients treated with conventional chemotherapy alone rarely develop thromboembolic events (2). Seven patients in whom we clinically detected these phenomena during ATRA therapy were successfully managed with heparin. In spite of some reports implicating thromboembolism in leukocytosis $(26,27)$, no relationship was noticed between these complications in our patients, and only one had leukocytes above $20 \times 10^{3} / \mathrm{mm}^{3}$ at the time of thrombosis. Some authors even recommend the prophylactic administration of low molecular weight heparin for one month in order to avoid thrombotic events in these patients (24).

ATRA given during induction did not improve the rate of CR or decrease mortality (28), but these patients developed less frequent and severe hemorrhagic complications, demanding a decreased amount of platelets and fresh frozen plasma, probably reducing the cost of care and the chance of transmission of blood-borne diseases when compared to patients managed with standard chemotherapy. The side effects of ATRA may 
be considered predictable, so that avoiding leukocytosis above $20 \times 10^{3} / \mathrm{mm}^{3}$ would significantly reduce the possibility of RAS and probably of intracerebral hemorrhage. Careful clinical monitoring of these patients would also allow an early diagnosis of thrombotic complications. Based on these observations we conclude that ATRA is an effective agent for the induction of CR in APL patients, and therefore we recommend its use for induction therapy in all patients with APL.

\section{References}

1. Stone RM \& Mayer RJ (1990). The unique aspects of acute promyelocytic leukemia. J ournal of Clinical Oncology, 8: 19131921.

2. Tallman MS \& Kwaan HC (1992). Reassessing the hemostatic disorder associated with acute promyelocytic leukemia. Blood, 79: 543-548.

3. Takatsuki H, Umemure T, Sadamura S, Yamashita S, Goto T, Abe Y, YufuY, Inaba S, NishimuraJ \& Nawata H (1995). Detection of minimal residual disease by reverse transcriptase polymerase chain reaction for the PML/RAR $\alpha$ fusion mRNA: a study in patients with acute promyelocytic leukemia following peripheral stem cell transplantation. Leukemia, 9: 889892.

4. Huang ME, Ye YC, Chen SR, Chai J R, Lu J X, Zhao L, Gu LJ \& Wang ZY (1988). Use of all-trans retinoic acid in the treatment of acute promyelocytic leukemia. Blood, 72: 567-572.

5. Chen $Z X$, Xue $Y Q$, Zhang $R$, Tao RF, Xia XM , Li C, Wang W, Zu WY, Yao XZ \& Ling BJ (1991). A clinical and experimental study on all-trans-retinoic acid-treated acute promyelocytic leukemia patients. Blood, 78: 1413-1419.

6. Fenaux $\mathrm{P}$, Le Deley MC, Castaigne $\mathrm{S}$, Archimbaud $E$, Chomienne $C$, Link $H$, Guerci A, Duarte M, Daniel MT, Bowen D, Huebner G, Bauters F, Fegueux N, Fey M, Sanz M, Lowenberg B, Maloisel F, Auzanneau G, Sadoun A, Gardin C, Bastion Y, Ganser A, J acky E, Dombret H, Chastang $C \&$ Degos L (1993). Effect of all transretinoic acid in newly diagnosed acute promyelocytic leukemia. Results of a multicenter randomized trial. Blood, 82: 3241-3249.

7. Bennet J M, Catavsky D, Daniel MT, Flandrin G, Galton D, Gralnick M \& Sultan C (1976). Proposals for the classification of the acute leukemias. British J ournal of Haematology, 33: 451-459.

8. Frankel SR, Eardley A, Lauwers G, Weiss M \& Warrel RP (1992). The 'retinoic acid syndrome' in acute promyelocytic leukemia. Annals of Internal Medicine, 117:
292-296.

9. Fleiss J L (1981). Statistical Methods for Rates and Proportions. 2nd edn. J ohn Wiley and Sons, New York.

10. Warrel RP, Frankel SR, Miller W, Itri L, Andreeff M, Jabulowski A, Gabrilove J, Gordon MS \& Dmitrovsky E (1991). Differentiation therapy of acute promyelocytic leukemia with tretinoin (all trans retinoic acid). New England J ournal of Medicine, 324: 1385-1394.

11. Cordonnier $C$, Vernant J $P$, Brun $B$, Heilmann MG, Kuentz $M$, Bierling $P$, Farcet J P, Rodet M, Duedari N, Imbert M, J ouault $H$, Mannoni P, Reyes F, Dreyfus B \& Rochant H (1985). Acute promyelocytic leukemia in 57 previously untreated patients. Cancer, 55: 18-28.

12. Leong KW, Bosco JJ \& Teh A (1994). Advantage of induction therapy with alltrans retinoic acid in acute promyelocytic leukemia in a country with limited transfusion resources: a Malaysian experience. European J ournal of Haematology, 53: 237-241.

13. Eardley $A M$, Heller $G \&$ Warrell J $r$ RP (1994). Morbidity and costs of remission induction therapy with all-trans retinoic acid compared to standard chemotherapy in acute promyelocytic leukemia. Leukemia, 8: 934-939.

14. Castaigne S, Chomienne C, Daniel MT, Berger R, Fenaux P \& Degos L (1990). All trans-retinoic acid as a differentiation therapy for acute promyelocytic leukemia. I. Clinical results. Blood, 80: 2176-2181.

15. Mckee J r LC \& Collins RD (1974). Intravascular leukocyte thrombi and aggregates as a course of mortality and morbidity in leukemia. Medicine, 52: 463-468.

16. Drapkin RL, Timothy SG, Dowling MD, Arlin Z, Mackenzie S, Kempin S \& Clarkson B (1978). Prophylatic heparin therapy in acute promyelocytic leukemia. Cancer, 41: 2484-2491.

17. Fenaux $\mathrm{P}$, Castaigne $\mathrm{S}$, Chomienne $\mathrm{C}$, Dombret H \& Degos L (1992). All-trans retinoic acid treatment for patients with acute promyelocytic leukemia. Leukemia, 6: 64-67.
18. Fenaux $\mathrm{P}$, Castaigne $\mathrm{S}$, Dombret $\mathrm{H}$, Archimbaud E, Duarte M, Chomienne C \& Degos L (1992). All-trans retinoic acid followed by intensive chemotherapy gives a high complete remission rate and may prolong remissions in newly diagnosed acute promyelocytic leukemia: a pilot study on 26 cases. Blood, 80: 2176-2181.

19. Vahdat L, Maslak P, Miller J r WH, Eardley A, Heller G, Scheinberg DA \& Warrel J $r$ RP (1994). Early mortality and the retinoic acid syndrome in acute promyelocytic leukemia: Impact of leukocytosis, low-dose chemotherapy, PMN/RAR- $\alpha$ isoform, and CD13 expression in patients treated with all-trans retinoic acid. Blood, 84: 38433849.

20. Chen GQ, Shen ZX, Wu F, Han J Y, Miao J M, Zhong HJ, Li XS, Zhao J Q, Zhu J, Fang ZW, Chen SJ , Chen Z \& Wang ZY (1996). Pharmacokinetics and efficacy of low-dose all-trans retinoic acid in the treatment of acute promyelocytic leukemia. Leukemia, 10: 825-828.

21. Fenaux $P$, Chastang $C \&$ Degos $L$ for the French APL group (1994). Treatment of newly diagnosed acute promyelocytic leukemia (APL) by a combination of all-trans retinoic acid (ATRA) and chemotherapy. Leukemia, 8: S42-S47.

22. Tallman MS, Andersen J W, Schiffer CA, Appelbaum FR, Feusner J H, Ogden A, Sheperd L, Willman C, Bloomfield CD, Rowe J M \& Wiemik PH (1997). All-trans retinoic acid in acute promyelocytic leukemia. New England J ournal of Medicine, 337: 1021-1028.

23. Wiley J S \& Firkin FC (1995). Reduction of pulmonary toxicity by prednisolone prophylaxis during all-trans retinoic acid treatment of acute promyelocytic leukemia. Leukemia, 9: 774-778.

24. Degos L (1994). Is acute promyelocytic leukemia a curable disease? Treatment strategy for a long-term survival. Leukemia, 8: S6-S8.

25. Rodeghiero F \& Castaman G (1994). The pathophysiology and treatment of hemorrhagic syndrome of acute promyelocytic leukemia. Leukemia, 8: S20-S26. 
26. Escudier SM, Kantarjian HM \& Estey EH (1996). Thrombosis in patients with acute promyelocytic leukemia treated with and without all-trans retinoic acid. Leukemia and Lymphoma, 20: 435-439.

27. Wang ZY, Chen Z, Huang W, Li XS, Lu J X,
Huang LA, Zhang FQ, Gu LJ , Ouyang RR $\&$ Chen SJ (1993). Problems existing in differentiation therapy of acute promyelocytic leukemia (APL) with all-trans retinoic acid (ATRA). Blood Cells, 19: 633-641.

28. Tallman MS, Andersen J W, Schiffer CA,
Appelbaum FR, Feusner J H, Ogden A, Sheperd L, Willman C, Bloomfield CD, Rowe J M \& Wiernik PH (1997). All-transretinoic acid in acute promyelocytic leukemia. New England J ournal of Medicine, 337: 1021-1028. 
The Pew Latin American Fellows Program in the Biomedical Sciences is providing support for young scientists from Latin America for post-doctoral training in the United States.

Ten Fellows will be selected in 1999. An award of $\$ 50,000$ will be provided as a salary stipend for the fellow during the period of training (2 years) and will be administered by the sponsoring U.S. institution. The sponsoring institution is expected to supplement the stipend with at least $\$ 5,000$ a year and provide medical benefits for the fellow. Following the two year fellowship, the Program will issue an additional $\$ 35,000$ award to the sponsoring institution to purchase equipment and supplies for the fellow to establish a laboratory in his or her home country.

Applicants must have held a Ph.D. and/or M.D. degrees, or equivalent, for no more than five years as of July 1, 1999. Strong preference will be given to those applicants with no previous postdoctoral training outside of their home country. Applicants are not required to have a commitment of a position and laboratory space after the fellowship. However, applicants must submit a written statement of intent to return to Latin America. Fellows must have a confirmed position and laboratory space in their home country by the end of the fellowship period in order to obtain the $\$ 35,000$ portion of the award.

Fellows will be selected on the basis of their promise as outstanding investigators, as well as the scientific merit of their research proposal, their record of training and how well their interests coincide with the laboratory of their sponsor in the United States. If potential applicants need assistance with the identification of an appropriate sponsoring laboratory in the United States, they may contact the Program O ffice before August 1, 1999. The Program will accept applicants from M exico, Central and South America. Applications may be obtained from the Regional Committee contact listed here for your country or from our website at http://futurehealth.ucsf.edu/pewlatin.html

The application deadline is 0 ctober 1,1999 . Winners will be notified in April 2000 and the fellowship should begin no later than August 2000.

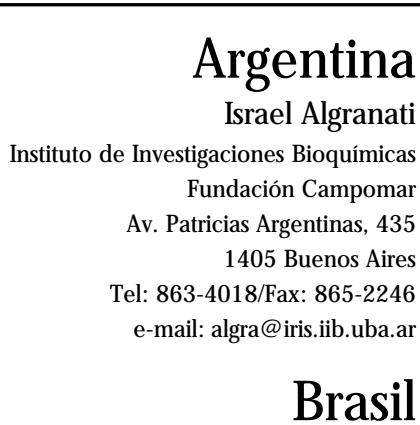

Carlos Eduardo Rocha-M iranda Vice President, Academia Brasileira de Ciências Rua Anfilófio de Carvalho, 29, 3ำ andar 20030-060 Rio de Janeiro, RJ, Brasil

Tel.: 220-4794/Fax: 240-4695 E-mail: cerm@ abc.org.br

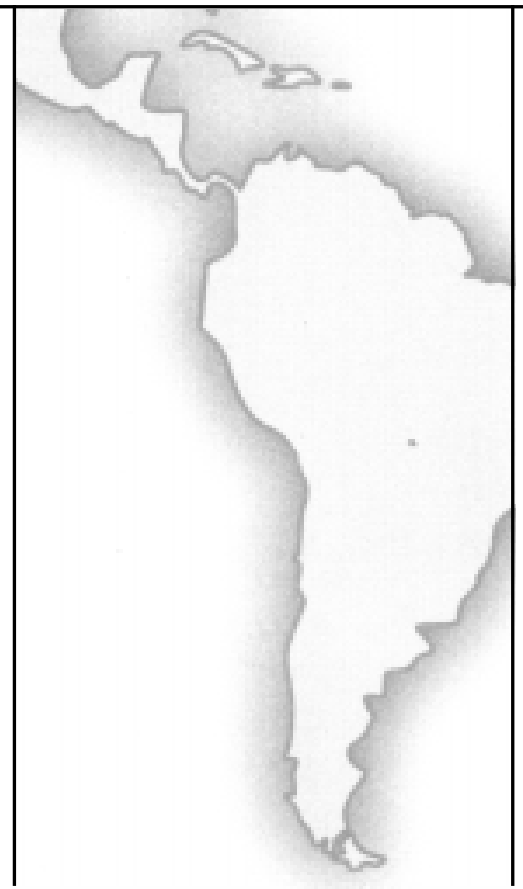

\section{Mexico}

\section{Hugo Aréchiga}

Facultad de Medicina UNAM

Ciudad Universitaria 04510

Mexico, D.F.

Tel: 622-0725/Fax: 550-8859

e-mail: arechiga@ servidor.unam.mx

\section{Chile}

Manuel A. Kukuljan, Ph.D.

Universidad de Chile

Departamento de Fisiologia y Biofisica

Casilla 70005 Santiago 7, Chile

Tel: 2-678-6310/Fax: 2-777-6916

e-mail: kukuljan@ bitmed.med.uchile.cl

\section{All other countries}

\section{Silvia Montano de Jiménez}

The Pew Latin American Fellows Program

3333 California Street, Suite 410

San Francisco, CA 94118

Tel: 415-476-5116/Fax: 415-476-4113

e-mail: montano@ itsa.ucsf.edu 